\title{
PENGEMBANGAN PRODUK UKIR BERBASIS 3 DIMENSI UNTUK MESIN CNC
}

\author{
Okta Andrica Putra
}

\section{Program Studi Sistem Komputer Universitas Putra Indonesia"YPTK" Padang}

* Email: okta.andrica@upiyptk.ac.id

\begin{abstract}
Abstrak
Telah dilakukan pengembangan tentang ukiran motif Minangkabau menggunakan mesin CNC dengan membuat desain 3D menggunakan Software aspire vector 8.5. pengujian dilakukan pada tiga buah ukiran motif Minangkabau yakni kaluak paku, itiak pulang patang dan aka cino saganggang. Pengujian dilakukan dengan ukuran media kerja $25 \mathrm{~cm}$ x $15 \mathrm{~cm}$ berbahan Multiplek, MDF dan kayu pinus. untuk waktu rata-rata pengerjaan ukiran kaluak paku adalah 40menit sedangkan manual bagi pengukir pemula adalam 2 sampai 3 bulan. Untuk pengejaan ukiran itiak pulang patang waktu rata-rata yang dibutuhkan adalah 15 menit, jika dilkerjakan secara manual bagi pemula memakan waktu 1 bulan, dan untuk pengerjaan ukiran aka cino saganggang dibutuhkan waktu rata-rata selama 25 menit, jika dikerjakan secara manual memakan waktu 1 hingga 2 bulan.
\end{abstract}

Kata kunci: Mesin CNC, Arduino, motif ukiran minangkabau

\section{Abstract [Times New Roman 10 points]}

A development has been carried out on carving Minangkabau motifs using a CNC machine by making 3D designs using aspire vector 8.5 software. The examiner was carried out on three Minangkabau motif carvings, namely kaluak nails, itiak back patang and aka cino saganggang. Tests were carried out with a work media size of $25 \mathrm{~cm} x 15 \mathrm{~cm}$ made of multiplex, MDF and wood. The average time for kaluak nail carving is 40 minutes, while the manual for beginner carvers is 2 to 3 months. For the spelling of carving itiak back in time the average time needed is 15 minutes, if done manually for beginners it takes 1 month, and for Akkino Saganggang carving work it takes an average of 25 minutes, if done manually for 1 to 2 months.

Keywords: CNC machines, Arduino, Minangkabau carving motifs

\section{PENDAHULUAN}

Proses kerajinanan secara manual membutuhkan waktu yang lama dan variasi desain juga terbatas. Dalam pengerjaan manual menggunakan alat pahat konvensional sehingga produk ukir selalu berbeda dari pengrajin satu dengan pengrajin yang lain dengan durasi pengerjaan yang berbeda pula, sehingga hasilnya juga berbeda baik dari sisi kualitas pahat, kepresisian dan karakter ukiran. Hasil survey pengerjaan produk dengan cara manual seperti di atas memang memungkinkan, saat hanya menghasilkan produk yang berjumlah sedikit. Pengukir sangat kesulitan jika mendapatkan pesanan dalam jumlah yang banyak. Hasil yang didapat tidak akan sama dan kecepatan produksi dibatasi oleh lelahnya pengukir. Alasan tersebut memperkuat dibutuhkannya $\mathrm{CNC}$, karena dengan $\mathrm{CNC}$ hasil produk dan kecepatan produksi dapat konsisten.

Ragam hias biasa digunakan pada karya seni, baik tradisional maupun modern. Ragam hias tersebut biasanya berbentuk pola berulang. Ragam hias juga merupakan perihal yang akan menyertai bidang gambar (lukisan atau jenis karya lainnya) dalam bentuk visual, ragam hias terdiri atas pola dan motif. Pola adalah penyebaran bentuk dan warna dalam suatu perulangan tertentu, sedangkan motif adalah tema dasar sebuah ragam hias. Dalam ragam hias tradisional musantara terdapat beragam bentuk pola dan motif. Ragam hias 
Minangkabau khususnya lebih banyak menampilkan motif binatang dan tumbuhan. contoh motif binatang dari ragam hias Minangkabau yang paling banyak dikenal adalah itiak pulang patang dan motif tumbuhannya adalah kaluak paku dan aka cino.

Motif kaluak paku diambil dari tumbuhan paku 'pakis', motif itiak pulang patang diambil dari hewan itik yang berbaris pulang saat sore hari. Ragam hias Minangkabau ini sangat banyak jumlahnya baik ragam bentuk visualnya maupun sumber pemerolehannya. Dari ukiran rumah gadang istano pagaruyung terdapat lebih dari 70 motif disamping itu, terdapat motif-motif yang berbeda hasil variasi dan gabungan beberapa motif dasar Minangkabau yang banyak ditemukan dalam iliminasi manuskrip yang ditemukan di beberapa wilayah sumatera barat, ditulis dalam jurnalnya Herry Nur Hidayat tentang pengembangan motfi ukiran rumah gadang untuk motif kain:revitalisasi dan pengembangan industry kreatif(Hidayat, 2018). Di sisi lain, ragam hias ukiran tradisional Minangkabau ini semakin jarang ditemui. Hal ini disebabkan oleh beberapa factor. Pertama, mahalnya biaya yang dibutuhkan untuk membuat ukiran tersebut. Keduam pengetahuan tentang motif ukiran tersebut. Pengetahuan tentang makna dan kesesuaian penggunaan adalah factor penting dalam pembuatan ukiran di rumah gadang. Hal inilah yang membuat masyarakat seolah enggan menggunakannya saat ini. Oleh karena itu perlu adanya usaha untuk kembali mengenalkan kekayaan tradisi Minangkabau kepada masyarakat pemilik tradisi tersebut.

\section{TINJAUAN LITERATUR}

\section{Ukir}

Ukir merupakan seni memahat material dengan pola maupun struktur hias yang dibuat cekung maupun cembung mengikuti alur gambar. Menilik pada konsep ukir, diungkapkan oleh gustami dalam bukunya seni kerajinan mebel ukir jepara bahwa banyak ukir yang di pahat diatas material kayu maupun baja dengan alat pahat yang terbuat dari besi maupun baja. Pada hakekatnya ukir adalah tekniknya bukan pada desian hias ukirnya, hal ini selalu menjadi hal yang salah dipahami terkait dengan produk jadi yang sering dibilang awan sebagai ukir karena motifnya.

Menurut raharjo, rubianto dan solechan,(Samsudi Raharjo, Rubijanto JP, 2015) dalam prosiding rancang bangun mesim ukir otomatis IBM mebel ukir kayu di Desa Banjar Agung Bangsri Kabupaten Jepara dapat dilakukan dengan cara perancangan mesin yang disetting khusus untuk dapat melakukan pekerjaan mengukir. Perubahan iklim industri yang cepat menuntut segmentasi pasar terkait teknik ukir yang kompatibel dengan hitungan ekonomis sehingga ukir merupakan komoditi teknik yang tidak bisa dipisahkan dari produk luarannya.

Menurut Khairuzaky Ukiran-ukiran yang digunakan merupakan gambaran keadaan alam sekitar, seperti tumbuhan, binatang, benda, dan manusia. Ukiran tersebut sesuai dengan falsafah hidup suku Minangkabau, alam takambang jadi guru, yang artinya alam terkembang jadi guru. Jika diartikan secara bebas, falsafah hidup tersebut menunjukkan bahwa alam merupakan medium pengajaran yang penting bagi suku Minangkabau(Khairuzzaky, 2018)

\section{CNC}

Computer Numerical Controller atau lebih dikenal dengan isitlah CNC merupakan rangkaian mesin dengan pola kerja programble intelligence untuk kepentingan eksekusi pekerjaan sistem Drilling (Guiping Yazhou dan Guangwen (2010). Melihat kekhususan kinerja msin CNC tidak menutup kemungkinan bahwa mesin CNC tetap dapat difungsikan dengan berbagai macam material termasuk kayu. komponen mesin CNC terdiri atas dua komponen dasar yakni komponen keras berupa fisik mesin dan komponen lunak berupa perangkat programmable atau software penggerak/executor.(Darmawanto \& Minardi, 2017) 
Prinsip kerja mesin CNC adalah dengan gerakan Vertical dan Horizontal dengan koordinat sumbu X Y dan $\mathrm{Z}$ dengan penggerak menggunakan motor stepper dan FanBelt format pemrograman NC (Numerical Computer) yang dikenal saat ini adalah G-Code. Format G-Code ini adalah format pertama dikenakkan dan dikhususkan untuk pemrograman NC. G-Code adalah nama umum Dari ISO 6983 atau Numerical Control Of Mechine of Address Words(Nugroho et al., 2019).

\section{Desain 3D}

Desain 3 dimensi merupakan bagian dari komponen senirupa dimana hanaya focus pada permasalahan konsep dan wujud implementasinya. Desain pada dasarnya memiliki unsur dan prinsip desain sehingga dalma menciptakan produk dalam bentuk visual memiliki tatanan atau aturan yang menjadi pertimbangan sehingga memberikan hasil produk yang dapat diterima oleh masyarakat (seventyani, 2013).Dalam konteks 3 dimensi yang dimaksud adalah desain dengan menggunakan material yang dapat secara langsung dilihat dalam konteks dimensi ruang sehingga terdapat ukuran volume atau kepadatan objek benda.

Konsep 3 dimensi memiliki unsur rancang yang lebih efisien, terpola dan aman hal ini disebabkan pola desain merupakan pola rancang bangun bukan eksekusi langsung. Meminimalkan kesalahan proses atau eksekusi produk dapat diatasi dengan rancangan desain yang baik dan terstruktur sehingga kemampuan desain 3 dimensi mampu memberikan citra ilusi dibenak konsumen akan produk yang akan dihasilkan nantinya

\section{METODOLOGI}

Lokasi, waktu, bahan dan peralatan. Tempat pelaksanaan kegiatan penelitian di laboratorium sistem komputer Universitas Putra Indonesia "YPTK" Padang dan Workshop Hobikayu Padang Blok E lantai 3 pasaraya padang Sebagai media partner. penelitian mulai dari Februari s.d November 2020. Bahan yang digunakan adalah multiplex, besi dan alumnium. Motif ukiran yang digunakan adalah itiak pulang patang, kaluak paku dan aka cino. Pengujian menggunakan bahan material MDF, Multiplex dan Kayu Pinus.

Mesin yang digunakan adalah mesin CNC router dengan dimensi kerja 1500mm x 1250 mm dengan sistem pendingin (collant) sistem penjepit, cutting tools bahan carbide jenis engraving bits sudut 60 dan straight bits diameter masing-masing $6 \mathrm{~mm}$.

Pelaksanaaan penelitian ini terdiri dari tahapan sebagai berikut :

1. Identifikasi kebutuhan pembuatan mesin CNC dengan luas area kerja $1500 \mathrm{~mm} \times 1250 \mathrm{~mm}$

2. Desain motif ukiran Minangkabau yang digunakan adalah Itiak Pulang Patang, Pucuak Paku dan Aka Cino dengan software aspire vectric dan Universal Gcode Sender untuk dikirim ke ardunino untuk dieksekusi

3. Bahan baku yang digunakan untuk membuat ukiran adalah multiplek, kayu jati belanda dan MDF. Memastikan bahwa mesin CNC dapat bekerja optimal dengan menggunakan berbagai Tool engraving yang tersedia.

4. Mesin CNC router 3 axis yang digunakan adalah buatan sendiri dengan anggaran Rp 25.000.000,dengan luas area kerja adalah $1500 \mathrm{~mm}$ x $1250 \mathrm{~mm}$ dengan menggunakan router berkecapata 5000 Rpm, 4 buah motor stepper, 4 buah motor driver, serta kombinasi alat menggunakan pentab dan koneksi Bluetooth.

5. Uji coba permesinan dilakukan dengan 3 bahan berbeda yakni MDF, Multiplex dan Kayu Pinus. Dalam ujicoba ini hal yang paling utama adalah pencarian nilai parameter paling tepat untuk menghasilkan ukiran terbaik. Proses iterasi nilai parameter CNC yang dilakukan sampai ada hasil ukir yang dapat digunakan untuk melakukan pemesinan ukiran Minangkabau yang sesungguhnya. 
6. Evaluasi merupakan langkah penting untuk mendapatkan informasi tentang parameter terbaik (putaran router, laju pemakanan, kedalaman potong,, jenis cutting tools) dikorelasikan dengan kualitas hasil ukiran dan keamanan terhadap peralatan dan mesin $\mathrm{CNC}$ router.

7. Hasil produk dari mesin CNC merupakan korelasi antara desain $3 \mathrm{D}$ dengan mesin CNC yang sudah valid atau antara desain dan hasil sudah memiliki tingkat kemiripan $100 \%$.

8. Finishing dilakukan dengan memberikan tampilan produk kreatif yang menarik dan mempunyai nilai jual dengan kualitas terbaik.

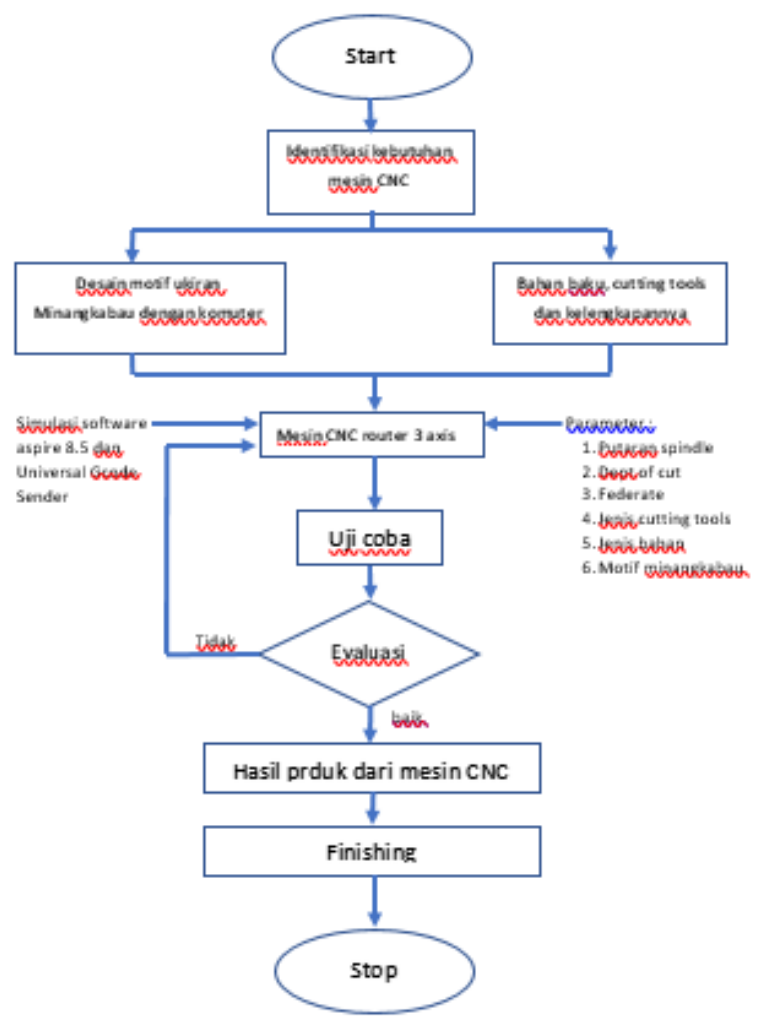

Gambar 1 : Skema Metode Penelitian

\section{HASIL DAN DISKUSI}

\subsection{Kaluak paku}

Pengujian pertama adalah gambar seni ukir Minangkabau dengan nama Kaluak paku. Biasanya ukiran ini berada pada dinding rumah gadang. Pembuatan manualnya bisa memakan waktu 2 hingga 3 bulan bagi pengukir pemula. Pada kategori pengukir profesional maka bisa memakan waktu hingga 3 minggu hingga 1 bulan dengan biaya cukup mahal

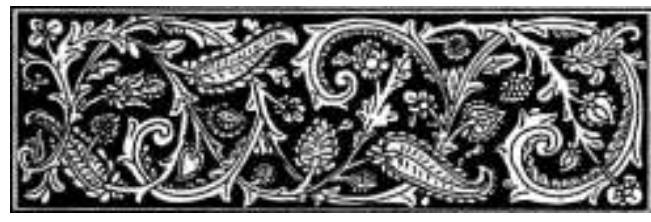

Gambar 2 : Kaluak Paku Dalam Bentuk 2D 
Selanjutnya gambar tersebut akan diimport ke dalam software aspire vector untuk dibuatkan desain 3D-nya. Berikut hasil pengolahan software aspire vector.

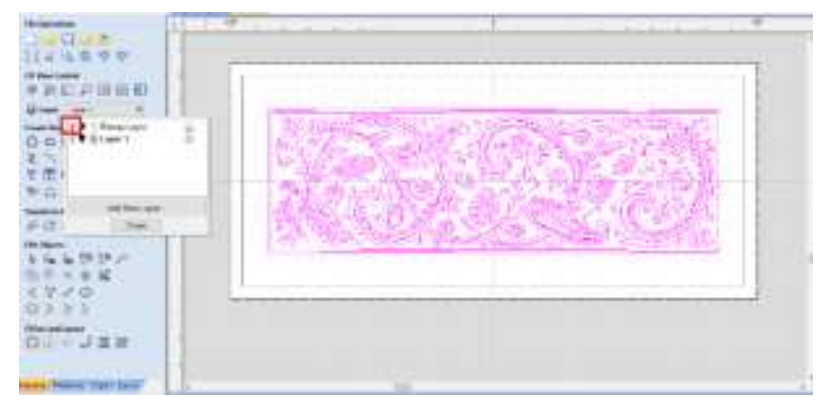

Gambar 3 : Import Gambar 2D ke Aspire Vectric

Gambar di dibawah adalah hasil olahan software 3D yang langsung dieksekusi oleh mesin CNC dengan lama waktu pengerjaan kurang lebih 40 menit dengan ukuran $25 \mathrm{~cm} \times 15 \mathrm{~cm}$.

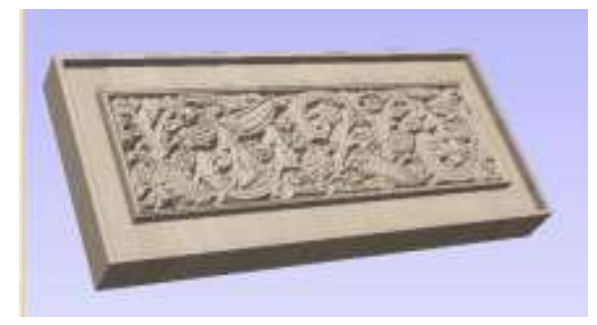

Gambar 4 : Hasil Desain 3D Kaluak Paku

\subsection{Itiak Pulang Patang}

Motif itik pulang petang merupakan bagian dari ornamen bangunan tradisional minangkabau, terutama rumah gadang. Motif ini dipahatkan pada kayu dan menjadi penghias dinding rumah gadang pada bidangbidang kecil seperti bawah jendela.

Pembuatan manualnya bisa memakan waktu 1 hingga 2 bulan bagi pengukir pemula. Pada kategori pengukir profesional maka bisa memakan waktu hingga 2 minggu hingga 1 bulan dengan biaya sedang

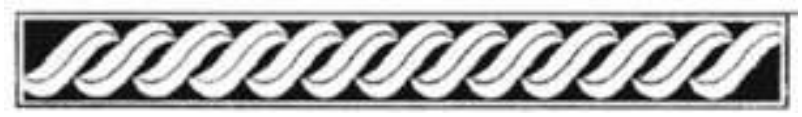

Gambar 5: Itiak Pulang Patang Dalam Bentuk 2D

Selanjutnya gambar tersebut akan diimport ke dalam software aspire vector untuk dibuatkan desain vector. Berikut hasil pengolahan software aspire vector : 


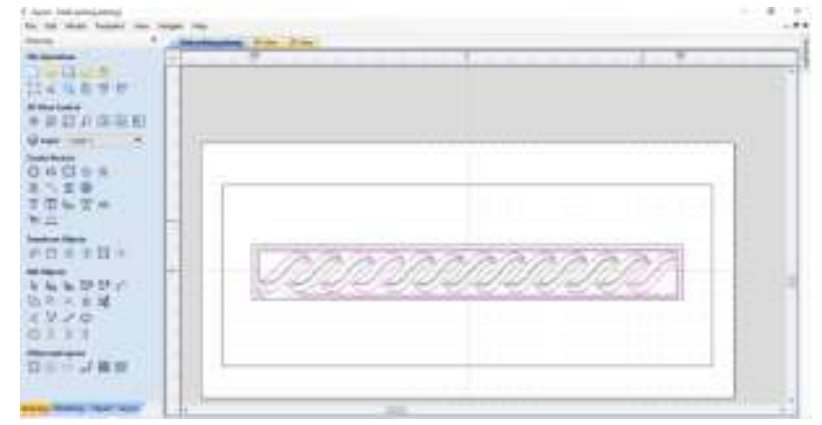

Gambar 6 : Import Gambar 2D ke Aspire Vectric

Gambar di dibawah adalah hasil olahan software 3D yang langsung dieksekusi oleh mesin CNC dengan lama waktu pengerjaan kurang lebih 10 menit dengan ukuran $25 \mathrm{~cm} \times 15 \mathrm{~cm}$

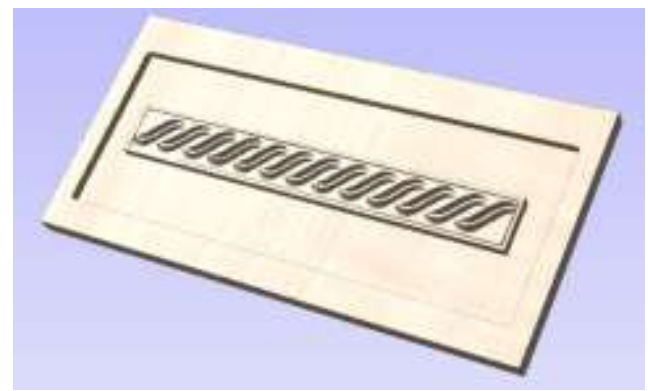

Gambar 7 : Hasil Desain 3D Itiak Pulang Patang

\subsection{Aka Cino Saganggang}

Motif aka cino dalam bentuk yang sederhana, mengisi bidang ukiran kecil di rumah gadang, selain itu, motif ini sering dijumpai pada peralatan rumah tangga. Bentuk dasar dari mtofi aka cino yakni garis melengkung berupa sulur dengan pola pengulangan berjajar dan dipadukan elemen tumbuhan lain seperti dedaunan, kuncup dan kelopak bunga seperti gambar dibawah ini :

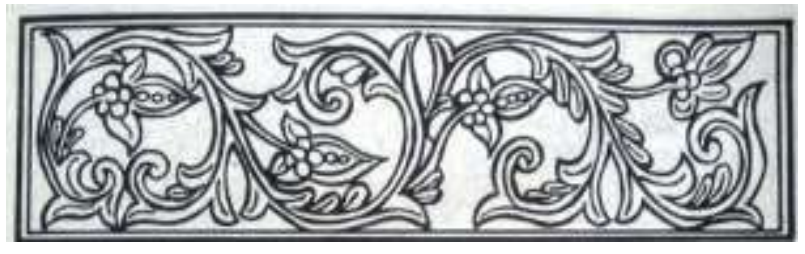

Gambar 8 : Aka Cino Sitanggang Dalam Bentuk 2D

Selanjutnya gambar tersebut akan diimport ke dalam software aspire vector untuk dibuatkan desain vector. Berikut hasil pengolahan software aspire vector: 


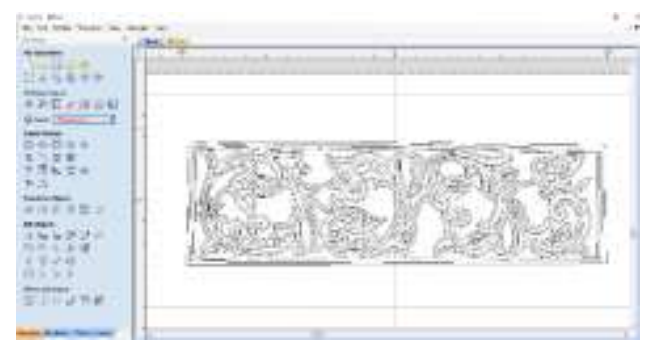

Gambar 9 : Import Gambar 2D ke Aspire Vectric

Gambar di dibawah adalah hasil olahan software 3D yang langsung dieksekusi oleh mesin CNC dengan lama waktu pengerjaan kurang lebih 25 menit dengan ukuran $25 \mathrm{~cm} \times 15 \mathrm{~cm}$ :

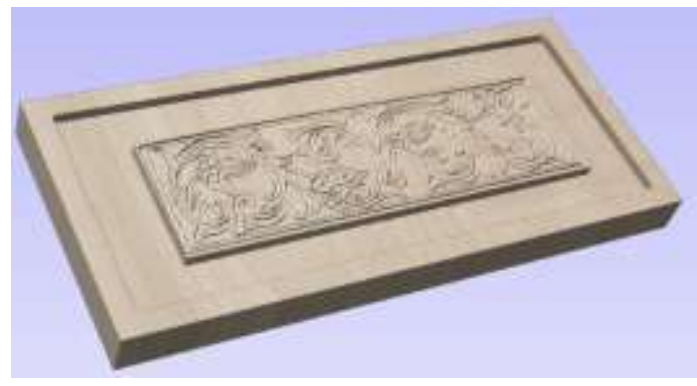

Gambar 10 : Hasil Desain 3D Aka Cino Saganggan

\section{Kesimpulan [Times New Roman 11 points]}

Berdasarkan hasil pengujian maka dapat diambil kesimpulan sebagai berikut:

a. Agar bentuk ukiran lebih sempurna maka hasil ukiran 3D dipengaruhi oleh besaran nilai pixel gambar yang didapat pada saat diterapkan ke mesin CNC

b. Gambar ukiran motif Minangkabau selama ini hanya dalam bentuk gambar maka Perlu adanya bentuk 3D dari masing-masing motif Minangkabau tersebut sehingga kekayaan budaya Minangkabau dapat dipertahankan

c. Penentuan media kerja seperti penggunaan kayu, multiplek dan bahan MDF juga harus diperhatikan karena berhubungan dengan kecepatan kerja mesin dan hasil.

d. Disarankan melakukan kalibrasi mesin CNC perlu dilakukan setiap kali akan membuat ukiran baru. Mengingat proses pengerjaan satu ukiran memakan waktu lebih dari 100 menit dengan media yang berbeda-beda

\section{REFERENSI}

[1] Darmawanto, E., \& Minardi, J. (2017). Pengembangan Produk Ukir Berbasis Desain 3 Dimensi Menggunakan Mesin Cnc Untuk Industri Mebel. Disprotek, 8(1), 67-80.

[2] Hidayat, H. N. (2018). PENGEMBANGAN MOTIF UKIRAN RUMAH GADANG UNTUK MOTIF KAIN: Revitalisasi dan Pengembangan Industri Kreatif. Jurnal IImiah Lingua Idea, 9(1).

[3] Khairuzzaky, K. (2018). Kajian Struktur Ragam Hias Ukiran Tradisional Minangkabau Pada Istano Basa Paguruyung. Titik Imaji, 1(1), 54-67. https://doi.org/10.30813/.v1i1.1090

[4] Nugroho, E. C., Nugroho, A., \& Hendriyanto, I. (2019). Prototipe Mesin CNC 2D Berbasis Arduino Uno. Go Infotech: Jurnal IImiah STMIK AUB, 25(1), 43. https://doi.org/10.36309/goi.v25i1.103

[5] Samsudi Raharjo, Rubijanto JP, S. (2015). Rancang bangun mesin ukir otomatis i. Prosiding SNST Ke-6 Tahun 2015, ISBN 978-6, 79-83. 